\title{
Influence of food regimes and seasonality on fatty acid composition in the ragworm
}

\author{
J. García-Alonso ${ }^{1, *}$, C. T. Müller ${ }^{2, *}$, J. D. Hardege ${ }^{1, * *}$ \\ ${ }^{1}$ Department of Biological Sciences, University of Hull, Hull HU6 7RX, UK \\ ${ }^{2}$ Cardiff School of Biosciences, Biomedical Building, Museum Avenue, Cardiff CF10 3US, UK
}

\begin{abstract}
Nereidid worms are well known to be key prey species for aquatic organisms, including economically important fish (e.g. plaice) and invertebrates (shrimps). Food regimes which include nereidids improve the reproductive fitness of cultured animals, i.e. the 'nereidid effect'. Aquaculture produces huge amounts of sludge, which might be recycled by feeding to the ragworm Nereis diversicolor. Here we analysed the fatty acid profiles in $N$. diversicolor over $1 \mathrm{yr}$ for a wild population and for ragworms fed with commercial fish food or eel sludge. The omega-3 ( $\omega-3)$ eicosapentanoic acid (20:5n3) was the most abundant fatty acid followed by palmitic (16:0), stearic (18:0) and oleic (18:1) acids. Biomass of the ragworms increased by $205 \%$ in worms fed with fish food and remained stable in worms fed with eel sludge, indicating the good adaptation of individuals to the culture conditions. Only under fish food regimes were significant increases observed in saturated and total unsaturated fatty acids compared to natural food regimes. However, the $\omega-3$ polyunsaturated fatty acids did not differ among food regimes, indicating that sludge from aquaculture is a good nutritive resource for $N$. diversicolor. This suggests the potential use of ragworms in aquaculture to reduce the production of waste and increase the reproductive fitness of cultivated animals.
\end{abstract}

KEY WORDS: Aquaculture - Fatty acids · Food regimes - Gas chromatography-mass spectrometry · GC-MS $\cdot$ Nereis diversicolor $\cdot$ Polychaetes

\section{INTRODUCTION}

Polychaetes, as the major taxonomic group in estuarine and marine ecosystems, occupy a largely infaunal habitat and play an important role in bioturbation, transferring organic materials and nutrients from the water column into the sediment and vice versa. The ragworm Nereis diversicolor is commonly found in large numbers in the intertidal zone of estuarine and brackish waters, normally in sediments of medium to high organic content (Kristensen 1983, Rouse \& Pleijel 2001). Its distribution stretches from the inner Baltic Sea, northwestern Europe and northeastern North America to the Mediterranean, Black and Caspian Seas (Smith 1977). Its abundance in the extreme environment of the intertidal requires $N$. diversicolor to tolerate temperatures from below zero to high sum- mer values and salinity from zero up to hypersaline conditions, as well as oxygen deficits and the presence of sulphide. This high level of adaptability allows the ragworm to be easily cultivated and is responsible for its characterisation as a good experimental animal (Smith 1977). Additionally, as an omnivore, it feeds on a variety of diets, ranging from bacteria to detritus.

Nereis diversicolor is often the dominant organism in the soft bottom of brackish water habitats and, due to its abundance, digestibility and high energy content, it plays a fundamental role as a prey species in the estuarine food web (e.g. for fishes and birds). Additionally, it is a predator of other benthic organisms and a scavenger (Perkins 1974, Heip \& Herman 1979). As prey, $N$. diversicolor may pass any compounds including natural fatty acids (FA) in their tissues further up the food 
chain, transferring such materials to the whole ecosystem (McLusky 1989).

Nereidid worms are commonly named omegaworms due to their high content of omega-3 ( $\omega-3)$ polyunsaturated fatty acids (PUFA) (Harrison 1991). This author mentions the key importance of polychaetes in the diet of shrimps successfully bred in captivity. Therefore, polychaetes and especially nereidids are used as a food item in aquaculture (Olive 1999).

The nutritional value of Nereis diversicolor was demonstrated by feeding ragworms to shrimp and fish. The feeding regime resulted in an increased number of eggs per spawning event for each female and increased egg viability and larval survival in shrimp (Briggs et al. 1994) and more rapid maturation in cultured prawns (D'croz et al. 1988, Luis \& Ponte 1993) and sole (Diniz 1992). Nereidid worms contain large amount of essential PUFA, which allows broodstock conditioning for egg production by crustaceans (Lytle et al. 1990, Olive et al. 1992). It is anticipated that this so-called 'Nereis effect' (Diniz 1992) is caused by the high content of PUFA in nereidids. Therefore, food regimes containing nereidids potentially improve the reproductive fitness of cultured animals. In parallel, aquaculture produces huge amounts of sludge, which in turn might be recycled by feeding to the ragworm N. diversicolor.

We investigated the composition and seasonal variation of FA during an annual cycle and under different food regimes. The objective of this work was to examine the FA profile in Nereis diversicolor from a wild population and compare it with worms cultivated using fish food or eel sludge as different food regimes. Gas chromatography coupled with mass spectrometry (GCMS) was employed to identify FA of $N$. diversicolor.

\section{MATERIALS AND METHODS}

Specimens. Nereis diversicolor were collected at 2 mo intervals from tidal mud flats in Cardiff Bay, Cardiff, UK $\left(51^{\circ} 27^{\prime} 09^{\prime \prime} \mathrm{N}, 3^{\circ} 10^{\prime} 44^{\prime \prime} \mathrm{W}\right)$, sized and weighed. Replicates of worm samples (1 $\mathrm{g}$ each, containing approximately 4 to 8 worms depending on the sizes) were obtained on each sampling day and stored at $-20^{\circ} \mathrm{C}$ until the analysis of fatty acid composition.

Different food regimes: fish food and eel sludge. Cultures were set up in 6 glass aquaria $(121 \times 38 \times$ $30 \mathrm{~cm}, 187$ l capacity). Each aquarium was sub-divided into 3 compartments $(40 \times 38 \times 30 \mathrm{~cm}, 621$ capacity) by the insertion of a polyethylene plate with a mesh centre $(13.5 \times 22.5 \mathrm{~cm})$ to allow a communal water flow. The aquarium was filled with a basal $(3 \mathrm{~cm})$ washed gravel layer and a top $(10 \mathrm{~cm})$ washed sand layer, before the addition of (approx. 50 l) $6 \%$ seawater. The water was re-circulated with the aid of a Fluval 303 filter pump (New World Aquatics). Specimens were at a density of 240 per compartment, equal to 1500 worms $\mathrm{m}^{-2}$ for $500 \mathrm{~d}$. Three of these aquaria received on average $1.1 \mathrm{~g}$ of commercial fish food (Tetramarin flakes, Tetra ${ }^{\circledR}$ ) per compartment per day, while in the remaining 3 aquaria, nereidid worms were periodically fed on average $78 \mathrm{ml}$ of sludge (approx. $1.3 \mathrm{~g}$ dry weight) per compartment per day. Aquaculture-derived sludge was obtained from the settlement tank of an eel aquaculture company (Eels Scotland) and contained an average of $16 \mathrm{~g}$ total solids $\mathrm{l}^{-1}$. Temperature and salinity values were monitored and maintained between 12 and $16^{\circ} \mathrm{C}$ and 5 to $7 \%$, respectively. For comparison, 5 worms were collected from the field at the same time as the feeding experiment ended (November).

Total lipids and FA extraction. Approximately $1 \mathrm{~g}$ wet weight worms were extracted twice with $30 \mathrm{ml}$ of chloroform:methanol $(2: 1, \mathrm{v}: \mathrm{v})$. The filtered extracts were washed once with aqueous potassium chloride $(\mathrm{KCl})$ solution $(8 \%)$ and once with a mixture of $8 \% \mathrm{KCl}$ and methanol $(1: 1, \mathrm{v}: \mathrm{v})$. The solvent was removed by rotary film evaporation and the residue weighed as total lipid and then dissolved in chloroform spiked with benzothiazolinone hydrazone (BTH) as an antioxidant. The dry weight of all extracted worms and samples was determined from the extraction residue.

Saponification and esterification. After removal of the solvent under a stream of nitrogen, the samples were refluxed for $1 \mathrm{~h}$ with $4 \mathrm{ml}$ of $1 \mathrm{M}$ potassium hydroxide in $95 \%$ ethanol. The reaction mixture was cooled, water added and 3 times extracted with hexanol ether $(1: 1, v: v)$. The extracts containing any nonsaponifiable compounds were washed with water, dried and stored at $-20^{\circ} \mathrm{C}$ for further analysis. The aqueous layer was acidified and the FA recovered by extracting with hexanol ether as described above.

Free FA were dissolved in methanol containing $1 \%$ sulphuric acid and kept in a vial at $100^{\circ} \mathrm{C}$ for $2 \mathrm{~h}$. Five $\mathrm{ml}$ of $5 \%$ sodium chlorine saline was added and the esters extracted twice with $5 \mathrm{ml}$ hexane. The extracts were washed with potassium bicarbonate and dried over sodium sulphate. After removal of the solvents, the esters were dissolved in $1.4 \mathrm{ml}$ hexane.

GC-MS analysis. The analyses were carried out on a Thermoquest GC-MS system comprising autosampler (Fisons AS 800), GC (Fisons 8000 series) and quadrupol mass spectrometer (Finnigan MD800). The GC was fitted with a split/splitless injection port which was operated splitless at $240^{\circ} \mathrm{C}$. The separation was performed on a poly-alkaline glycol (PAG)-coated fused silica column (SUPELCO, $30 \mathrm{~m} \times 0.25 \mathrm{~mm}$ i.d., $0.25 \mu \mathrm{m}$ coating). Helium carrier gas was at $1 \mathrm{ml} \mathrm{min}^{-1}$ flow rate. A linear temperature programme was used starting at $140^{\circ} \mathrm{C}$ and ending at $220^{\circ} \mathrm{C}$ with a rate of 
$1^{\circ} \mathrm{C} \mathrm{min}^{-1}$. Samples and standards were diluted 1:10 with hexane prior to analysis. One $\mu \mathrm{l}$ of sample was injected and the spectra recorded after a solvent delay of $4 \mathrm{~min}$. Quantification was carried out against an external standard comprising 37 saturated and unsaturated fatty acid methyl esters (SUPELCO, 37 Component FAME Mix).

Statistical analysis. The FA patterns from the wild population over the seasons and those from cultures with fish food and eel sludge were analysed. Due to the large amount of variables (30 FA), principal component analysis (PCA) was carried out and a factor was obtained, representing the FA with major effects in the total variance. The factor coordinates of cases, based on covariance were compared using 1-way ANOVA (SPSS 16.0). Groups of different types of FA (saturated, monounsaturated, PUFA and $\omega-3$ PUFA) were compared among different food regimes with 1-way ANOVA analysis. Level of significance used was $p<0.05$. Tests for homogeneity of variance (Levene) and normality (Shapiro-Wilks) were done prior to ANOVA analyses.

\section{RESULTS}

\section{Seasonal variation of FA in Nereis diversicolor}

As a percent of total dry weight, mean percent lipid content of worms collected from the field was highest in winter (mean $\pm \mathrm{SD}=31.5 \pm 3.7 \%$ ) compared to the other seasons. However, the percentage of FA was lowest in winter $(3.7 \pm 1.1)$ and highest in spring $(9.9 \pm 2.92$, Table 1$)$.

Concentration of FA over the seasons showed that in winter, levels of FA are minimal. In spring, the amount of FA increases considerably while, in summer, the relative amount of FA in the body of the ragworms decreases slightly (Fig. 1). Saturated FA represented around 10\% and PUFA reached $40 \%$ of the total lipids in spring (data not shown). In fact, the concentration of PUFA (ANOVA, $F_{3,12}=5.40$, $\mathrm{p}<0.05), \omega-3$ PUFA (ANOVA, $F_{3,12}=$ 5.22, $\mathrm{p}<0.05)$ and monounsaturated FA (ANOVA, $F_{3,12}=3.94, \mathrm{p}<0.05$ ) were higher in spring compared to winter (Fig. 1).

The seasonal variation of FA in Nereis diversicolor was mainly due to an increase in unsaturated FA. The $\omega-3$ PUFA repre- sent the major constituent of PUFA over the seasons, reaching $81.4 \%$ in spring. However, the $\omega-3: \omega-6$ ratio did not notably vary among the seasons ranging from $6.08 \%$ (autumn) to $12.0 \%$ (spring) (Table 1, Fig. 1).

The main FA were the $\omega-3$ PUFA eicosapentaenoic acid (EPA, 20:5n3) and docosahexaenoic acid (DHA, 22:6n3), the saturated palmitic acid (16:0) and the monosaturated oleic acid (18:1, Table 1). Some important FA appeared in relatively low concentrations, including arachidonic acid (AA, 20:4n-6) and other (-3 PUFA, e.g. 18:3n3 and 20:3n3. Several other FA appeared at trace levels.

Table 1. Nereis diversicolor. Fatty acid (FA) profiles (mean $\pm \mathrm{SD} ; \mu \mathrm{g}$ FA $\mathrm{mg}^{-1}$ dry wt) of specimens collected from the field at Cardiff Bay, Penarth (on natural feeding regimes, $\mathrm{n}=12$ ) using 3 replicates per season over an annual cycle. PUFA: polyunsaturated fatty acids; AA: arachidonic acid; EPA: eicosapentaenoic acid; DHA: docosahexaenoic acid; t.l.: total lipid; Sat: saturated FA; Unsat: unsaturated $\mathrm{FA}_{i} \omega$-3: omega-3 polyunsaturated $\mathrm{FA}_{i}$ $\omega-6$ : omega-6 polyunsaturated FA

\begin{tabular}{|lrcrr|}
\hline Fatty acids & Winter & Spring & Summer & Autumn \\
\hline Saturates & & & & \\
C14:0 & $0.06 \pm 0.03$ & $0.37 \pm 0.17$ & $0.22 \pm 0.02$ & $0.2 \pm 0.07$ \\
C15:0 & $0.37 \pm 0.09$ & $0.95 \pm 0.21$ & $1.10 \pm 0.12$ & $1.3 \pm 0.24$ \\
C16:0 & $3.78 \pm 1.17$ & $9.67 \pm 2.34$ & $6.64 \pm 0.66$ & $7.5 \pm 2.03$ \\
(palmitic acid) & & & & \\
C17:0 & $0.66 \pm 0.11$ & $1.34 \pm 0.21$ & $1.29 \pm 0.11$ & $1.6 \pm 0.21$ \\
C18:0 & $2.77 \pm 0.55$ & $6.00 \pm 0.98$ & $4.68 \pm 0.60$ & $5.0 \pm 0.83$ \\
C20:0 & $0.01 \pm 0.01$ & $0.02 \pm 0.01$ & $0.00 \pm 0.00$ & $0.0 \pm 0.00$ \\
C22:0 & $0.17 \pm 0.03$ & $0.28 \pm 0.14$ & $0.21 \pm 0.04$ & $0.3 \pm 0.28$ \\
C21:0 & $0.00 \pm 0.00$ & $0.00 \pm 0.00$ & $0.00 \pm 0.00$ & $0.0 \pm 0.00$ \\
C23:0 & $0.00 \pm 0.00$ & $0.01 \pm 0.01$ & $0.00 \pm 0.00$ & $0.0 \pm 0.00$ \\
C24:0 & $0.00 \pm 0.00$ & $0.00 \pm 0.00$ & $0.00 \pm 0.00$ & $0.00 \pm 0.00$ \\
Monounsaturates & & & & \\
C14:1 & $0.02 \pm 0.02$ & $0.01 \pm 0.00$ & $0.02 \pm 0.02$ & $0.0 \pm 0.01$ \\
C15:1 & $0.00 \pm 0.00$ & $0.00 \pm 0.00$ & $0.00 \pm 0.00$ & $0.0 \pm 0.01$ \\
C16:1 & $0.87 \pm 0.37$ & $2.63 \pm 0.87$ & $0.95 \pm 0.13$ & $0.8 \pm 0.29$ \\
C17:1 & $0.08 \pm 0.02$ & $0.06 \pm 0.05$ & $0.21 \pm 0.20$ & $0.5 \pm 0.41$ \\
C18:1n9c & $0.66 \pm 0.13$ & $1.36 \pm 0.28$ & $0.86 \pm 0.33$ & $1.5 \pm 0.44$ \\
C18:1n9t & $0.94 \pm 0.33$ & $1.88 \pm 0.29$ & $1.58 \pm 0.22$ & $1.2 \pm 0.31$ \\
C20:1 & $0.65 \pm 0.15$ & $1.41 \pm 0.25$ & $0.96 \pm 0.15$ & $1.1 \pm 0.23$ \\
C22:1n9 & $0.00 \pm 0.00$ & $0.04 \pm 0.02$ & $0.07 \pm 0.06$ & $0.1 \pm 0.05$ \\
C24:1 & $1.19 \pm 0.68$ & $0.29 \pm 0.19$ & $0.09 \pm 0.01$ & $0.1 \pm 0.05$ \\
Polyunsaturates (PUFA) & & & \\
C18:2n6c & $0.97 \pm 0.29$ & $2.17 \pm 0.57$ & $1.82 \pm 1.21$ & $4.7 \pm 0.47$ \\
C18:2n6t & $0.11 \pm 0.06$ & $0.04 \pm 0.05$ & $0.00 \pm 0.00$ & $0.1 \pm 0.10$ \\
C18:3n6 & $0.12 \pm 0.05$ & $0.60 \pm 0.09$ & $0.39 \pm 0.11$ & $0.1 \pm 0.05$ \\
C18:3n3 & $0.24 \pm 0.12$ & $1.06 \pm 0.48$ & $1.42 \pm 0.20$ & $1.9 \pm 0.48$ \\
C20:2 & $0.71 \pm 0.16$ & $1.76 \pm 0.33$ & $1.11 \pm 0.30$ & $2.0 \pm 0.65$ \\
C20:3n6 & $0.00 \pm 0.00$ & $0.16 \pm 0.04$ & $0.10 \pm 0.04$ & $0.1 \pm 0.11$ \\
C20:4n6 (AA) & $1.47 \pm 0.25$ & $2.13 \pm 0.42$ & $2.14 \pm 0.05$ & $3.2 \pm 0.82$ \\
C20:3n3 & $0.09 \pm 0.07$ & $0.59 \pm 0.14$ & $0.55 \pm 0.04$ & $0.5 \pm 0.36$ \\
C20:5n3 (EPA) & $20.37 \pm 4.24$ & $57.74 \pm 11.03$ & $37.40 \pm 2.36$ & $42.4 \pm 10.19$ \\
C22:2 & $0.03 \pm 0.02$ & $0.33 \pm 0.06$ & $0.03 \pm 0.01$ & $0.1 \pm 0.08$ \\
C22n6n3 (DHA) & $1.45 \pm 0.17$ & $5.84 \pm 1.52$ & $2.83 \pm 0.53$ & $6.6 \pm 3.53$ \\
Profile variables & & & & \\
$\%$ t.1. in dry wt & $31.53 \pm 3.74$ & $19.94 \pm 5.94$ & $14.70 \pm 1.46$ & $19.64 \pm 8.37$ \\
\% FA in dry wt & $3.78 \pm 1.09$ & $9.89 \pm 2.92$ & $6.7 \pm 0.95$ & $7.81 \pm 2.54$ \\
Sat/Unsat ratio & $0.32 \pm 0.03$ & $0.24 \pm 0.01$ & $0.3 \pm 0.00$ & $0.24 \pm 0.01$ \\
\% $\omega-3$ in Unsat & $76.91 \pm 1.06$ & $81.37 \pm 1.90$ & $80.5 \pm 0.56$ & $76.01 \pm 1.17$ \\
$\omega-3: \omega-6$ & $8.23 \pm 1.77$ & $12.03 \pm 1.95$ & $8.70 \pm 4.10$ & $6.08 \pm 1.18$ \\
\hline
\end{tabular}




\section{FA profiles of Nereis diversicolor on different food regimes}

The ragworms showed a very good adaptation to the systems. The percentage of biomass at the end of the experiment, as compared to the beginning, was $205 \%$ for Nereis diversicolor fed with fish food and $100 \%$ for those fed with eel sludge. The weight of the worms fed on fish food effectively doubled, while that of worms fed with eel sludge stayed stable, indicating good culture conditions for these worms. In addition, in the culture systems the worms were larger than those collected from the field (data not shown).

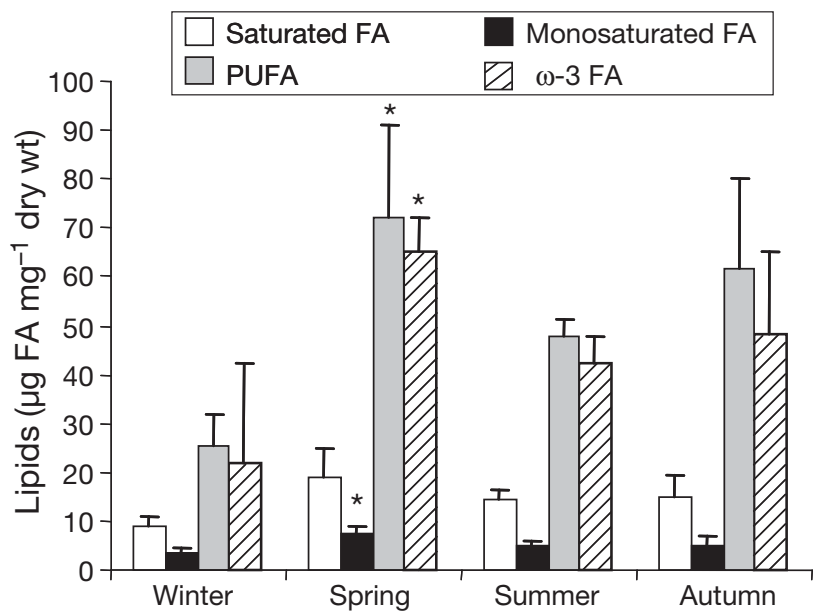

Fig. 1. Nereis diversicolor. Seasonal variation of fatty acids (FA) (mean $+\mathrm{SD}$ ) in ragworms on natural food regimes $(\mathrm{n}=$ 12 , using 3 replicates per season over an annual cycle). Concentrations of saturated, unsaturated and omega-3 ( $\omega-3)$ FA are in $\mu \mathrm{g} \mathrm{mg}^{-1}$ dry wt. PUFA: polyunsaturated fatty acids ${ }^{*}$ Significant differences $(p<0.05)$ between spring and winter

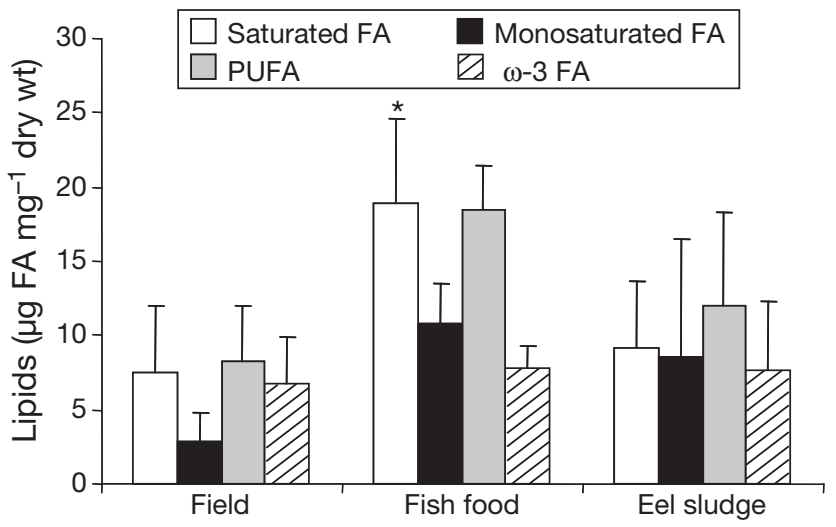

Fig. 2. Nereis diversicolor. Saturated fatty acid (FA), monounsaturated FA, polyunsaturated FA (PUFA) and $\omega$-3 PUFA concentrations (mean $\pm \mathrm{SD}$ ) in ragworms from field $(\mathrm{n}=5)$, fish food $(n=4)$ and eel sludge $(n=11)$ food regimes. ${ }^{*}$ Significant differences $(p<0.05)$ between field and fish-food-fed worms
Total lipid and FA contents were determined for worms taken from the field and for worms fed on fish food and eel sludge. The FA profiles of all worm samples showed differences regarding the content of specific FA (Table 2). However, an analysis of the general FA profile did not show significant differences between the experiments. The main factor of the PCA with an eigenvalue of 68.2 represented $58.3 \%$ of the total variance with a high loading of palmitic acid, 16:1, 18:1n9c, 18:1n9t, 18:2n6c and DHA, all FA with a strong influence on the total variance. The factor coordinates of each replica did not show any significant difference (ANOVA, $F_{2,19}=0.890, p=0.429$ ), indicating that the different food regimes do not affect the general FA profile. Additionally, the percentage of total FA increased in worms fed with fish food, but this was not statistically significant (ANOVA, $F_{2,19}=3.023, \mathrm{p}=$ $0.084)$.

Concentration of saturated, monounsaturated, PUFA and $\omega$-3 PUFA were compared among food regimes (Fig. 2). Saturated FA significantly increased in worms fed with fish food (ANOVA, $F_{(2,19)}=4.854, \mathrm{p}<0.05$ ) but not in those fed with eel sludge, and the saturated: unsaturated ratio decreased considerably in worms fed with eel sludge (ANOVA, $F_{2,19}=3.965, p<0.05$ ). The worms taken from the field were generally found to be lower in unsaturated FA. Monounsaturated, PUFA and $\omega$-3 PUFA did not fluctuate among food regimes, although the $\omega-3: \omega-6$ ratio decreased considerably in worms fed with both fish food (ANOVA, $F_{2,19}=4.854$, $\mathrm{p}<0.001$ ) and eel sludge (ANOVA, $F_{2,19}=4.854, \mathrm{p}<$ $0.05)$ compared to those obtained from the natural environment.

Nereis diversicolor showed a FA profile similar to that observed under natural conditions when fed commercial fish food (Table 2). An interesting observation is the accumulation of palmitic acid as well as $\omega-3$ FA such as 18:3n-3, EPA and DHA.

The fatty acid profile of worms fed on eel sludge showed higher values of palmitic acid and elaidic acid (C18:1n9t) and moderate concentration of several FA such as 14:0, 16:1, 18:0, 18:1n9c and 18:2n6c. Interestingly, the FA profile which appeared in the worms fed with eel sludge is characterised by a high concentration of palmitic acid; EPA and oleic acid (C18:1n9c). Palmitic acid appears in relatively high concentrations amongst the worms in all food regimes, although the ragworms fed with fish food showed higher values than those fed eel sludge or from the field. This is probably the reason that saturated FA in cultured worms were significantly different to those in the natural regime (ANOVA, $F_{2,19}=$ $4.854, \mathrm{p}<0.05)$.

The concentrations of $\omega$-3 PUFA remained similar in all the different treatments, showing no significant dif- 
Table 2. Nereis diversicolor. Fatty acid (FA) profiles (mean \pm $\mathrm{SD}_{i} \mu \mathrm{g}$ FA mg ${ }^{-1}$ dry wt) and lipid and FA ratios of individuals cultured under different food regimes: natural conditions (field, $\mathrm{n}=5$ ), and fed with fish food $(\mathrm{n}=4)$ or fed with eel sludge worms $(n=11)$. Abbreviations as in Table $1 .{ }^{*} p<0.05$, ${ }^{* *} \mathrm{p}<0.001$

\begin{tabular}{|lccc|}
\hline Fatty acids & Field & Fish food & Eel sludge \\
\hline Saturates & & & \\
C14:0 & $0.33 \pm 0.27$ & $1.03 \pm 0.42$ & $0.53 \pm 0.49$ \\
C15:0 & $0.69 \pm 0.25$ & $0.34 \pm 0.13$ & $0.32 \pm 0.22$ \\
C16:0 & $3.80 \pm 2.18$ & $13.29 \pm 5.00$ & $6.04 \pm 2.75$ \\
(palmitic acid) & & & \\
C17:0 & $0.64 \pm 0.47$ & $0.41 \pm 0.27$ & $1.88 \pm 4.31$ \\
C18:0 & $1.05 \pm 0.64$ & $3.44 \pm 1.09$ & $1.29 \pm 1.10$ \\
C20:0 & $0.56 \pm 0.64$ & $0.01 \pm 0.01$ & $0.00 \pm 0.01$ \\
C21:0 & $0.00 \pm 0.00$ & $0.00 \pm 0.00$ & $0.02 \pm 0.05$ \\
C22:0 & $0.34 \pm 0.30$ & $0.31 \pm 0.37$ & $0.04 \pm 0.05$ \\
C23:0 & $0.15 \pm 0.11$ & $0.04 \pm 0.03$ & $0.05 \pm 0.06$ \\
C24:0 & $0.00 \pm 0.00$ & $0.00 \pm 0.01$ & $0.03 \pm 0.04$ \\
Monosaturates & & & \\
C14:1 & $0.00 \pm 0.00$ & $0.01 \pm 0.01$ & $0.01 \pm 0.02$ \\
C15:1 & $0.00 \pm 0.00$ & $0.00 \pm 0.00$ & $0.00 \pm 0.00$ \\
C16:1 & $0.58 \pm 0.33$ & $2.80 \pm 0.80$ & $1.13 \pm 0.64$ \\
C17:1 & $0.17 \pm 0.15$ & $0.03 \pm 0.02$ & $0.05 \pm 0.04$ \\
C18:1n9c & $1.32 \pm 1.06$ & $5.07 \pm 1.64$ & $2.91 \pm 3.37$ \\
C18:1n9t & $0.31 \pm 0.19$ & $1.02 \pm 0.84$ & $0.93 \pm 0.76$ \\
C20:1 & $0.38 \pm 0.42$ & $1.75 \pm 0.22$ & $2.05 \pm 2.98$ \\
C22:1n9 & $0.06 \pm 0.04$ & $0.09 \pm 0.01$ & $0.68 \pm 1.66$ \\
C24:1 & $0.08 \pm 0.08$ & $0.06 \pm 0.05$ & $0.10 \pm 0.15$ \\
Polyunsaturates (PUFA) & & \\
C18:2n6c & $0.44 \pm 0.18$ & $3.98 \pm 0.85$ & $1.19 \pm 0.93$ \\
C18:2n6t & $0.00 \pm 0.00$ & $1.36 \pm 1.91$ & $0.14 \pm 0.38$ \\
C18:3n6 & $0.01 \pm 0.03$ & $0.02 \pm 0.02$ & $0.10 \pm 0.21$ \\
C18:3n3 & $0.30 \pm 0.17$ & $0.75 \pm 0.16$ & $0.30 \pm 0.19$ \\
C20:2 & $0.35 \pm 0.30$ & $2.75 \pm 0.33$ & $1.28 \pm 0.74$ \\
C20:3n6 & $0.01 \pm 0.02$ & $0.52 \pm 0.10$ & $0.23 \pm 0.18$ \\
C20:4n6 & $0.60 \pm 0.27$ & $1.91 \pm 0.20$ & $1.07 \pm 0.42$ \\
C20:3n3 & $0.05 \pm 0.06$ & $0.18 \pm 0.07$ & $0.16 \pm 0.12$ \\
C20:5n3 (EPA) & $6.23 \pm 2.83$ & $5.27 \pm 1.04$ & $5.53 \pm 3.20$ \\
C22:2 & $0.04 \pm 0.06$ & $0.09 \pm 0.04$ & $0.11 \pm 0.06$ \\
C22n6n3 (DHA) & $0.22 \pm 0.14$ & $1.58 \pm 0.48$ & $1.44 \pm 1.20$ \\
Profile variables & & & \\
\% t.1. in dry wt & $25.5 \pm 22.9$ & $19.7 \pm 3.7$ & $23.3 \pm 6.7$ \\
\% FA in dry wt & $1.9 \pm 1.0$ & $4.8 \pm 1.3$ & $3.0 \pm 1.9$ \\
Sat/Unsat ratio & $0.62 \pm 0.1$ & $0.63 \pm 0.1$ & $0.48 \pm 0.0 *$ \\
\% $\omega-3$ in Unsat & $61.9 \pm 7.6$ & $27.2 \pm 6.4 * *$ & $37.9 \pm 13.5 *$ \\
$\omega-3: \omega-6$ & $5.73 \pm 1.45$ & $0.91 \pm 0.33 * *$ & $3.26 \pm 1.94 *$ \\
\hline
\end{tabular}

ferences between food regimes (ANOVA, $F_{2,19}=0.088$, $\mathrm{p}=0.917$ ). In particular, the concentrations of EPA were high and similar between worms from the cultures and the field. However, the reduction of the $\omega-3: \omega-6$ ratio in worms fed with fish food was highly significant (ANOVA, $F_{2,19}=4.85, \mathrm{p}<0.001$ ) and there was a significant decrease in those fed with eel sludge (ANOVA, $\left.F_{2,19}=11.117, \mathrm{p}<0.05\right)$, indicating a selective accumulation of $\omega-6$ PUFA, such as $18: 2 \mathrm{n} 6 \mathrm{c}$, 18:2n6t, 20:3n6 and 20:4n6 (Table 2).

\section{DISCUSSION AND CONCLUSIONS}

The lipid content in Nereis diversicolor from Cardiff Bay was found to be generally higher than that observed in populations from Portugal (Luis \& Passos 1995). The seasonal trend, however, was similar to that found by Luis \& Passos (1995), with the total lipid content peaking in winter and showing minimum levels in summer.

The fatty acid profiles of the ragworm Nereis diversicolor analysed here showed low levels occurring during the winter, a time of low food supply and accordingly higher consumption of stored reserves (e.g. lipids). In spring, when food availability increases, the amount of FA increases accordingly. With the population in summer made up of a high proportion of juveniles, FA levels decrease slightly until the autumn, when the values reach levels similar to those observed in spring (Fig. 1). Saturated FA did not change much, while total unsaturated and $\omega-3$ FA were responsible for the major changes over the season. These results for FA content differ in their concentrations during the year from those of Luis \& Passos (1995) for a population of $N$. diversicolor in the Tagus estuary (Lisbon, Portugal). Luis \& Passos (1995) found a different seasonal variation of the FA profile, with lower concentration of FA in summer and the highest in winter. The difference in latitude and consequently differences in photoperiod and temperature, which directly regulate reproduction in nereidids, might explain the difference between these 2 populations. Similar results were found when 2 populations of the clam Mercenaria mercenaria were compared, one from Canada and other from Florida (USA). Lower concentration of PUFA was found in the second population (Bonnet et al. 1974). Furthermore, Ueda et al. (1974) demonstrated that environmental temperature plays a key role in regulating PUFA synthesis in this species.

Palmitic acid (16:0) was found at high concentration in all the samples, indicating that this saturated fatty acid may be an important item in 'fatty' diets. Palmitic acid is the first metabolite of FA synthetase and the initial product of de novo lipogenesis, and a precursor of many kinds of molecules with physiological relevance such as membrane lipids, fats and waxes (Nelson \& Cox 2000). In another annelid, the oligochaete Eisenia fetida, palmitic acid, octadecanoic acid and oleic acid were identified as major FA with maximum concentrations detected during the sub-mature stage (Rouabah-Sadaoui \& Marcel 1995).

EPA represented one of the most abundant FA in all of the Nereis diversicolor samples analysed. It is one of the major components of fish oil, a precursor of prostaglandins and thromboxane, and cannot be synthesised de novo in humans. The relatively low levels of the biosynthetic precursor of all other $\omega-3$ PUFA, 
linolenic acid (18:3n-3), observed in $N$. diversicolor suggested a strong route of fatty acid metabolism to produce these important essential FA. Unexpectedly, EPA concentrations did not change among the food regimes (Table 2). DHA, another $\omega$-3 PUFA and a major constituent of fish oils, was observed in all samples, and like EPA, its concentrations did not differ amongst the different food treatments.

In its natural environment, Nereis diversicolor feeds on a variety of sources, predominantly grazing algae around the entrance to its burrows, or filter-feeds on suspended organic material. The feeding mode is determined by the particle size (Riisgard 1994). This diverse feeding behaviour was observed in the feeding trials where the ragworm accepted a variety of food sources ranging from mostly organic matter (eel sludge) to a balanced fish food diet. The ragworms showed, in some case, exceptionally high growth rates, which resulted in individuals larger than any worms collected from the field in Cardiff Bay (data not shown).

Modes of feeding, reproduction and the environment influence FA composition in marine organisms (Graeve et al. 1997, Dalsgaard et al. 2003). Studies on seasonal variation of FA in molluscs Mytilus spp. over 2 consecutive years unexpectedly found that in a particular month in one year the concentration of palmitic acid was the lowest and the DHA the highest, while in the same month in the next year they were the highest and the lowest, respectively (Joseph 1982). In this work on food regimes, the worms collected in the field at the end of the experiment presented very low levels of some key PUFA such as EPA and DHA (Table 2).

Bradshaw et al. (1990) and Luis \& Passos (1995) suggested that diet could be the major factor influencing lipid composition in Nereis diversicolor. Our findings confirm partially these reports with respect to composition and metabolism of lipids in this species. However, the general FA composition of $N$. diversicolor fed with fish food or eel sludge was not significantly different from the FA composition of a wild population, suggesting that the final FA profile in worms is a result of metabolic capacity and culture conditions, in particular, the associated microfauna and microflora. Microorganisms might produce and increase the concentrations of some FA. This implies that within the experimental systems, the metabolic pathways from worms and microorganisms have a potential capacity of FA elongation and/or desaturation. This FA synthesis is highly advantageous when N. diversicolor is used as an organic food source in aquaculture. Ragworms compensate for possible alterations in the FA profile of e.g. fish and crustaceans in aquaculture systems, such as the commercial farms established recently in many European waters, which might otherwise compromise their nutritional value.
Although the percentage of $\omega-3 \mathrm{FA}$ in worms fed with fish food or eel sludge was less than in worms from the wild, the concentration values were maintained at a constant level. This was due to an increase in saturated and total unsaturated FA. Overall, the FA profiles did not differ greatly amongst worms taken from the field and those from the different experimental food regimes.In partcular, the concentration of $\omega-3$ PUFA did not decrease under culture conditions, indicating that cultured Nereis diversicolor is an excellent source of FA. The results of the present study also lead to an understanding of why polychaetes, and especially $N$. diversicolor, are one of the most important food sources in coastal environments worldwide and have immense value for commercial culture of vertebrates and invertebrates (Olive 1999).

This work showed that Nereis diversicolor fed with sludge produced considerable amounts of EPA and significant amounts of DHA and AA, all compounds required for a good reproductive performance in prawns (Meunpol et al. 2005) or fish. DHA is not only an essential FA, but is also effective in increasing the tolerance to stress in fish larvae (Kanazawa 1997). Our work also supports the idea that nereidids are excellent $\omega$-3 FA sources, and these key FA are maintained under culture conditions with little influence by the diet regime the worms are kept under.

The organic sludge, which stems from wastewater treatment in aquaculture, if eaten and converted into worm biomass by Nereis diversicolor could, therefore, be used as a high quality diet in aquaculture. The process would consequently offer a sustainable solution to the existing problem of organic pollution caused by aquaculture and stimulate significantly the development of closed, food-recycling, aquaculture systems.

Acknowledgements. We are grateful for the financial support given by the European Union (Project FAIR GT96 0603). Special thanks go to Dr. J. Sawchik and to anonymous reviewers of the Journal for their invaluable comments and suggestions.

\section{LITERATURE CITED}

Bonnet JC, Sidwell VD, Zook EG (1974) Chemical and nutritive values of several fresh and canned finfish, crustaceans and molluscs. II. Fatty acid composition. Mar Fish Rev $36: 8-21$

Bradshaw SA, O'Hara SCM, Corner EDS, Eglington G (1990) Dietary changes during herbivory and coprophagy by the marine invertebrate Nereis diversicolor. J Mar Biol Assoc UK 70:771-787

Briggs MRB, Brown JH, Fox CJ (1994) The effects of dietary lipid and lecithin levels on the growth, survival, feeding efficiency, production and carcass competition of postlarval Penaeus monodon (Fabricius). Aquacult Fish Manag 25:279-294

D'croz L, Wong L, Justine G, Gupta M (1988) Prostaglandins 
and related compounds from the polychaete worm Americonuphis reesi (Onuphidae) as possible inducers of gonad maturation in penaeid shrimps. Rev Biol Trop 36: 331-332

Dalsgaard J, St John M, Kattner G, Müller-Navarra D, Hagen W (2003) Fatty acid trophic markers in the pelagic marine environment. Adv Mar Biol 46:225-340

Diniz MT (1992) Aspects of the potential of Solea senegalensis for aquaculture. J Aquacult Fish Manag 23:515-520

Graeve M, Kattner G, Piepenburg D (1997) Lipids in Arctic benthos: Does the fatty acid and alcohol composition reflect feeding and trophic interactions? Polar Biol 18:53-61

Harrison KE (1991) Crustacean reproduction nutrition. Crustac Nutr Newsl 7:62-70

Heip C, Herman R (1979) Production of Hediste diversicolor O. F. Müller (Polychaeta) in a shallow brackish water pond. Estuar Coast Mar Sci 8:297-305

Joseph JD (1982) Lipid composition of marine and estuarine. invertebrates. II. Mollusca. Prog Lipid Res 21:109-153

Kanazawa A (1997) Effects of docosahexaenoic acid and phospholipids on stress tolerance of fish. Aquaculture 155: 129-134

Kristensen E (1983) Ventilation and oxygen uptake by three species of Nereis (Annelida: Polychaeta). I. Effects of hypoxia. Mar Ecol Prog Ser 12:289-297

Luis OJ, Passos AM (1995) Seasonal changes in lipid content and composition of the polychaete Nereis (Hediste) diversicolor. Comp Biochem Physiol B 111:579-586

Luis OJ, Ponte AC (1993) Control of reproduction of the shrimp Penaeus kerathurus held in captivity. J World Aquacult Soc 24:31-39

Lytle JS, Lytle TF, Ogle JT (1990) Polyunsaturated fatty acid profiles as a comparative tool in assessing maturation

Editorial responsibility: Anne Hershey,

Greensboro, North Carolina, USA diets of Penaeus vannamei. Aquaculture 89:287-299

McLusky DS (1989) The estuarine ecosystem, 2nd edn. Chapman \& Hall, New York

> Meunpol O, Meejing P, Piyatiratitivorakul S (2005) Maturation diet based on fatty acid content for male Penaeus monodon (Fabricius) broodstock. Aquacult Res 36: 1216-1225

Nelson DL, Cox MM (2000) Lehninger principles of biochemistry, 3rd edn. Worth Publishers, New York

Olive PJW (1999) Polychaete aquaculture and polychaete science: a mutual synergism. Hydrobiologia 402:175-183

Olive PJW, Bury N, Cowin PBD, Smithard RR (1992) Commercial production of polychaetes for angling: implications for mainstream aquaculture. Spec Publ Eur Aquacult Soc 14:241-242

Perkins EJ (1974) The biology of estuaries and coastal waters. Academic Press, Burlington, MA

Riisgard HU (1994) Filter-feeding in the polychaete Nereis diversicolor: a review. Aquat Ecol 28:453-458

Rouabah-Sadaoui L, Marcel R (1995) Sugars and lipids of the clitellum and cocoon albumin in Eisenia fetida Sav (Annelida Oligochaeta). Reprod Nutr Dev 35:537-548

Rouse GW, Pleijel F (2001) Polychaetes. Oxford University Press, New York

Smith RI (1977) Physiological and reproductive adaptations of Nereis diversicolor to life in the Baltic Sea and adjacent waters. In: Reish DJ, Fauchald K (eds) Essays on polychaetous annelids in memory of Dr. Olga Hartman. The Allan Hancock Foundation, University of Southern California, Los Angeles, CA, p 373-390

Ueda T (1974) Changes in the fatty acid composition of short neck clam with reference to environmental mud temperature. Bull Jpn Soc Sci Fish 40:949-957

Submitted: September 27, 2007; Accepted: July 30, 2008

Proofs received from author(s): September 11, 2008 